\title{
A Comparative study of the VAT/GST Complexity in India, Singapore, Australia, Korea and New Zealand
}

\author{
Shwetha S \\ Gokhale Institute of Politics and Economics, India
}

\begin{abstract}
The increasing complexity of legal systems has many origins, which are worth a deeper analysis. This paper is an attempt to unveil the complexity in the Value Added Tax (VAT) or Goods and Services Tax (GST) driven by policy and legislative structure. The selected sections of the GST/VAT like Registration, Refunds, Input Tax Credit (ITC), Return Filing, Place and Value of Supply are analysed. The Complexity Index produced by the Office of Tax Simplification (OTS) in the UK is used to determine the relative complexity of the countries. This examines the usefulness of the OTS Complexity Index for making international comparisons by applying it to VAT or GST in India, Australia, New Zealand, Korea and Singapore. It finds some striking differences in the complexity of the taxes in these countries. For instance, India's complexity index is found to be greater than other countries including Australia and New Zealand which themselves are considered to be complex. This paper suggests that by creating an international index based on the OTS method would make a major contribution to the development of a new approach in tax simplification in the VAT or GST domain.
\end{abstract}

Keywords: Readability, Tax Compliance, Tax Complexity

\section{Introduction}

Today's legal systems are complex and highly interdependent. Complex legislation can create uncertainties about the law. This can impose unnecessary burdens on business and restrict the ability of those affected by the law to understand their legal rights and obligations. The GST of India has been considered as one of the most complex legislation in the world. So, a comparison of India with other complex GST/VAT laws is a pertinent research. An important step towards tax simplification is measuring and monitoring the level of tax complexity with the help of an index. Such an index can be interpreted as a summary indicator of the overall complexity of a tax system at a particular point in time, so a series of such an index can be used to monitor the changing level of tax system complexity of a country over time. (Evans \& Tran-Nam, 2013)

In December 2012 the Office of Tax Simplification (OTS) published the first iteration of its Complexity Index ${ }^{1}$. The index is meant to be a methodology for assessing the relative

$\begin{array}{lllr}{ }^{1} \text { See } & \text { OTS } \quad \text { Complex } & \text { Index } & \text { Methodology } \\ & & & \text { paper: } \\ & & \text { info@icbme.org } & \\ \text { www.icbmeconf.org } & & \end{array}$


complexity of various factors within a section of tax legislation and so deriving an overall rating for complexity within the tax system across different pieces of tax legislation. Following the publication of the complexity index methodology in December 2012, the OTS have been refining and improving the index. A third version also got published in 2015.

In its second iteration, the index has been separated into two distinct parts. The first aims to measure underlying complexity, whilst the second aims to capture the impact of complexity. Underlying Complexity is the intrinsic complexity found in the structure of the tax which consists of policy and legislative complexity whereas the impact of Complexity is a combination of both the cost of compliance to an individual taxpayer and the aggregated cost of compliance for all taxpayers. The scope of this paper is limited to the relative measurement of the underlying complexity of countries like India, Australia, New Zealand, Korea and Singapore taking into account the legislative and policy areas of the legislation. Using these four countries is a particularly relevant way of assessing the applicability of the Complexity Index in different jurisdictions because, of course, all these four countries have different cultural, language, legal and political backgrounds. Both legislative and policy complexity uses two measures each, such as the number of exemptions, and number of finance acts passed to amend the original legislation for measuring the policy complexity and Gunning-Fog

readability index for calculating the policy complexity (The OTS Complexity index Version 2, 2013) Hence, this paper attempts to measure the policy and legislative complexity of VAT or GST of India with other countries at a time when the law is mostly criticized on a global level for its complex construction.

\section{Defining tax complexity}

Tax complexity has many dimensions and could plausibly be defined in different ways. It apparently means different things to different people depending on their biases, perspectives or research interests. For example, to a tax lawyer, tax complexity may refer to the difficulty with which a body of tax legislation can be read, understood and applied in various practical situations. To a tax accountant, tax complexity refers to the time he/she needs to expend in order to prepare an income tax return or to provide tax advice (which may include tax planning or assistance with tax objections or appeals). To a businessperson, tax complexity means the time and monetary costs spent in complying with the requirements of business tax laws. The list goes on. Despite the different interpretations, there seems to be universal agreement that tax complexity is itself a complex concept. (Evans \& Tran-Nam, 2013)

The literature has identified four aspects of complexity of the tax system namely predictability, enforceability, difficulty and manipulability. Predictability and enforceability basically pertain to the tax law, while difficulty and manipulability refer to taxpayers' responses to the tax law ${ }^{2}$. Other discussions in the literature have followed more or less the same vein, admittedly with different expressions or more elaboration McCaffery ${ }^{3}$ observes a separation of three main types as between technical, structural and compliance complexity. Cooper points out that tax

https://www.gov.uk/government/uploads/system/uploads/attachment_data/file/193493/ots_complexity_in

dex_methodology_paper.pdf

${ }^{2}$ See Slemrod (1989) in the 'Complexity, Compliance Costs, and Tax Evasion'

${ }^{3}$ Both authors have offered some input to the methodology of the OTS tax complexity index. 
complexity contains within it the dimensions of predictability, proportionality, consistency, compliance, administration, coordination and expressionand his contribution may be seen as a more detailed version of Slemrod's concept.. (Budak \& James)

\section{Need for a Complexity Index}

Tax complexities lead to a significant part of the political debate that is needed for the simplification of tax systems. However, it is not easy to achieve simplification in a complex socio-economic environment. Currently, there are lot of criticisms about the complex way of drafting the VAT or GST

legislation coupled with the increase in the rate of changes to the original act by way of umpteen number of notifications, schedules and rules. This nesseciates the need for simpler VAT or GST law. Countries like Australia and New Zealand have attempted to simplify their taxes but with very limited success. Also, there is a long standing argument about the complex formulation of the GST act of India.

Simplification in a way means reducing the number of taxes and leaving in place only those easier to pay and collect. It would also be necessary to draft plain and understandable laws, reduce distortions and harmonise taxes at national or federal and local level. A simple tax system increases transparency and reduces number of points of contact between businesses and tax authorities. Other advantages include lower administrative costs, lower compliance costs, fewer errors, fewer economic distortions and more transparency and accountability. Thus, the development of a summary indicator of the overall complexity of a tax system at a particular point in time is necessary. Such an index would not only enable assessment of the changing level of a country's tax system complexity over time, but may also facilitate comparisons of the relative complexity of different countries' tax systems in future. (Evans \& Tran-Nam, Towards the Development of a Tax System, 2013)

\section{Formats in Other Countries}

In countries like the United States an empirical framework was developed for measuring relative legal complexity. This framework is based on 'knowledge acquisition', an approach at the intersection of psychology and computer science, which can take into account the structure, language, and interdependence of law. The method considers three parameters of complexity such as structure, language, and interdependence (Katz \& Bommarito, 2013)

The poor readability of the legislation is a possible cause of Brazil's tax law complexity which led to a study on evaluating the readability of Brazilian tax law. The study adopted the most traditional measures of readability analysis such as Flesch Readability Ease Score (FRES) and average sentence length (ASL). The study revealed that the selected texts have a low level of readability, with the use of long sentences and words, which requires users to have a high-level education. (Martinez \& Silva, 2019)

A study was done in Germany to unveil the complexity in legal texts driven by structural, lexical and syntactical properties. Readability was measured by taking into account lexical and structural properties of the text, e.g. Flesch Reading Ease (FRE). The FRE is calculated as follows FRE german $_{1}=180-$ ASL- $\left(58.5^{*} \text { ASW }\right)^{4}$; (ASL: Average Sentence Length, ASW: Average Number of Syllables Per Word) Interestingly, the readability metrics inherently represent far

more textual properties than the formula takes into account. This is because of the dependencies throughout textual entities, e.g. word, frequency, vocabulary variety, lexical ambiguity, phonetic, etc. (Waltl \& Matthes)

\footnotetext{
${ }^{4}$ The constants reflect language depending properties.
} 
In 1993, the Australian Government set up the Tax Law Improvement Project (TLIP) which was considered a housekeeping project designed to re-phrase, but not to change, the existing legislation. Like other countries' initiatives, TLIP contributed to a change in the language and presentation of law. The aim was to rewrite the law with a better structure, make it easier to understand, and make it more user-friendly. However, there has not been a comprehensive analysis of the project to date. The TLIP was completed by the end of 2013; unfortunately, it had not reached its desired targets like the UK and the New Zealand initiatives but at least there were some considerable improvements. (Budak \& James, The Level of Tax Complexity: A Comparative Analysis Between the UK and Turkey Based on the OTS Index, 2018)

The UK Office of Tax Simplification (OTS) is developed a methodology for measuring the relative complexity of different parts of the UK tax system to derive a tax complexity index. This development is addressed primarily for tax administrations which are setting out to tackle what is meant by tax complexity. The aim for the UK is to come up with a practical tool to help the OTS rank, and so prioritise areas of the HMRC tax code, which would benefit from putting specialist resource into simplification of the appropriate parts of the system. Such work is multidisciplinary working across drafting legislation, developing tax policy under political priorities, public sector economists, tax practitioners, and tax officials at the end of the chain working to collect the right amount of tax. (Jones, Rice, Sherwood, \& Whiting, 2014)

This methodology adopted by OTS was used in a comparative study of the level of complexity in Turkey and the U.K. with respect to personal income tax, corporate income tax, VAT and inheritance tax. It was found that in both countries income tax is easily the most complex tax and therefore may have the most potential for simplification measures. (Budak \& James, The Level of Tax Complexity: A Comparative Analysis Between the UK and Turkey Based on the OTS Index, 2018) This study is in lines with the above methodology where relative complexity of VAT/GST laws are compared among countries like India, Australia, New Zealand, Korea and Singapore based on the construction of a complexity index derived from policy and legislative complexity metrics.

\section{Methodology}

Inspired by the literature that empirically analyses the tax law's complexity level, the research adopted its insights from the OTS methodology for computing a complexity index. The OTS index is a relative rather than an absolute measure of complexity and its aim is to provide an indication of which areas of tax legislation are considered to be particularly complex compared to others. This paper narrows its scope to the computation of an index based only on the policy and legislative complexities of the underlying act unlike the OTS methodology which also captures the impact of complexity measured by the cost of compliance. Instead of making a comparison based on the complexity of the areas within a single tax law, the paper compares the GST/VAT laws in different countries (India, Australia, Korea, New Zealand and Singapore) based on the complexity index. The selected chapters from the VAT/GST like Registration, Refunds, Input Tax Credit (ITC), Return Filing, Place and Value of Supply are considered for the analysis. These areas of the tax are considered to be more complicated in its drafting in all the five countries taken.

The complexity of a tax system can be minimised if some broad guidelines are followed when designing policy, and legislation. To develop the index indicators are chosen based on the three areas of the policy implementation process and uses two measures of complexity for each as explained below (The OTS Complexity index Version 2, 2013):

Policy complexity 
1. Number of exemptions - In the first iteration the number of exemptions was originally under legislative complexity, but it is felt that a modified version, which also accounts for exemptions, is more appropriate here. It is established that much of the complexity within a tax system stems from the existence of exemptions and special cases. Increasing the number of exemptions also increases the complexity, as it increases the complexity in deciding whether or not a taxpayer is exempt from tax. The reduction in the number of taxpayers affected is reflected in the impact of complexity, which will be discussed later in this paper.

2. The number of Finance Acts with changes- This criterion is retained from the first iteration because change is a significant contributor to complexity. As with the number of exemptions, it is more appropriate to include this as policy complexity rather than legislative, as much of the change in the Finance Acts is because of changes in policy.

\section{Legislative complexity}

3. The Gunning-Fog readability index - This is retained from the first iteration because it gives a comparative indication of how easy the text itself is to read. It is a weighted average of the number of words per sentence, and the number of long words per word. An interpretation is that the text can be understood by someone who left full-time education at a later age than the index. Other measures are available, but generally involve similar calculations and for these purposes the main requirement is consistent appraisal across legislation.

4. Number of pages of legislation - This measure gives an objective indication of how long the legislation is. This measure is entirely separate from the policy complexity: a complex policy can be expressed in simple, short legislation, and a simple policy in longer legislation.

A weighting system has been adopted on a range of 1 to 10 wherein 1 indicates a country with a simple tax law and 10 indicates one with the complex law. This gives a simple overall impression of relative complexity among countries. The weighting system is designed in a way so that each country is assigned equal weights when considering the four measures to get the final complexity score.

Feature scaling ${ }^{5}$ has been used as a method to standardize the range of independent variables or features of data. In data processing, it is also known as data normalization and is generally performed during the data pre-processing step. The general formula is given as

$$
\begin{aligned}
X^{\prime}= & X^{-\min (X)} \\
& \max (X)-\min (X)
\end{aligned}
$$

The term $\min (\mathrm{X})$ represents an indicators lowest value across all the countries while $\max (\mathrm{X})$ represents the highest. Also, $\mathrm{X}$ is the value of the indicator for a complexity measure and $\mathrm{X}$ ' denotes the weighted value of an indicator. This formula would always produce a score between 0 and 1 . Consequently, it gives a much smoother presentation, and removes the need to adjust

\footnotetext{
${ }^{5}$ Also known as min-max scaling or min-max normalization, is the simplest method and consists in rescaling the range of features to scale the range in $[0,1]$ or $[-1,1]$.
} 
the weightings constantly. At the same time, this formula gives an opportunity to compare the complexity of taxes across countries. The aggregation formula to arrive at the complexity index is given by

$R^{\prime}+L^{\prime}+G^{\prime}+P^{\prime}$

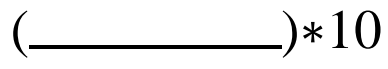

$--($ ii) 4

Where R', L', G', and P' represent the respective standardized values of number of exemptions, changes to legislation, Gunning-Fog Readability index and number of pages of legislation computed the same way as equation (i) and aggregated to a single value as in equation (ii) to get the complexity index which ranges from 1 to 10 .

\section{Analysis}

For the purpose of analysis each country's tax law has been compiled into separate documents. For each country a set of assumptions were taken before analysing the VAT/GST acts. The assumptions are given according to the respective indicators of policy and legislative complexities as below:

- The exemptions mentioned in multiple sub-sections pertaining to a single area is taken to be a single exemption or relief

- The chapters on Registration, Refunds, ITC, Return Filing, Place and Value of Supply if not mentioned in the original act and if they are released later, the information is taken from the respective notifications or schedules as the that's considered.

- The Australian GST is compiled into a single document from two different volumes of the New Tax System Act of 1999.

- Explanations mentioned in the CGST Act 2017 are not taken. The CGST rules are included. The Place of Supply is taken from IGST Act

- The base year ${ }^{6}$ taken for various countries are given below:

\begin{tabular}{|l|l|}
\hline India & 2017 \\
\hline Australia & 2010 \\
\hline Korea & 2000 \\
\hline New Zealand & 1990 \\
\hline Singapore & 2000 \\
\hline
\end{tabular}

\footnotetext{
${ }^{6}$ The base year is fixed based on the amendments released and the availability of data of various countries. If a particular country has not released any amendment in a couple of years after the original act the base year is fixed from the year it released the amendments.
} 
The table below shows the computation of the complexity matrix of India, Australia, New Zealand, Korea and Singapore as follows:

\begin{tabular}{|c|c|c|c|c|c|}
\hline & \multicolumn{2}{|c|}{ Policy complexity } & \multicolumn{2}{|c|}{ Legislative complexity } & \multirow[t]{2}{*}{$\begin{array}{l}\text { Complexity } \\
\text { Index }\end{array}$} \\
\hline & $\begin{array}{l}\text { Number of } \\
\text { Exemptions }\end{array}$ & \begin{tabular}{|l|} 
Changes to \\
Legislation
\end{tabular} & $\begin{array}{l}\text { Gunning- } \\
\text { Fog } \\
\text { Readability }_{\text {index }}{ }^{7}\end{array}$ & 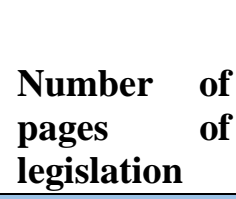 & \\
\hline $\min (x)$ & 11 & 7 & 12.71 & 11 & \\
\hline $\operatorname{Max}(x) \min (x)$ & 26 & 30 & 6.96 & 44 & \\
\hline India & 37 & 37 & 19.67 & 55 & 10.0 \\
\hline Australia & 11 & 8 & 14.39 & 22 & 1.3 \\
\hline $\begin{array}{l}\text { New } \\
\text { Zealand }\end{array}$ & 28 & 7 & 19.26 & 28 & 5.0 \\
\hline Singapore & 24 & 15 & 18.91 & 39 & 5.7 \\
\hline Korea & 11 & 9 & 12.71 & 11 & 0.2 \\
\hline
\end{tabular}

Source: Based on analysis

Comparison

Though there are difficulties in comparing levels of complexity in different countries due to their dissimilarities with respect to the tax legislation and systems but it may be possible to find some common features and comparable data. Thus, all indicators chosen should be objective and standardized for comparison. The OTS index-based methodology used in this study helps in this.

The number of exemptions in India is more than three times that of in Korea-India has 37 exemptions but Korea has only 11. Australia and Korea show an equal number of exemptions in the Acts. New Zealand has the second highest number of exemptions. With respect to changes to legislation again India scores high followed by Singapore. Australia is having the least number of legislative changes.

The Gunning-Fog Readability index of India and New Zealand are higher compared to other countries

followed by Singapore and Australia respectively. The number of pages of legislation ${ }^{8}$ is highest for India followed by Singapore. Using the aggregation formula (ii) the overall complexity is computed. It is found that the underlying complexity of India is highest with a value of 10 and Korea has the lowest complexity with a value of 0.2 .

\section{Conclusion}

Simplifying a tax system has considerable benefits but it is only one of a range of important factors that are involved in tax design. The OTS was established in the UK with this aim of simplification on July 20, 2010, to provide independent advice on options regarding the existing complexity of the tax system. In contrast, the countries like India, Australia, Korea, Singapore and New Zealand do not have such specific projects or offices primarily concerned with tax simplification.

\footnotetext{
${ }^{7}$ Computed from the website gunning-fog-index.com

${ }^{8}$ Only five chapters such as Registration, Refunds, Input Tax Credit (ITC), Return Filing, Place and Value of Supply are used.
} 


\section{$4^{\text {th }}$ International Conference on BUSINESS, MANAGEMENT \& ECONOMICS}

Comparative analyses between countries are even harder, of course, because of differences in culture and so on and each country has its own approach to measuring tax simplicity. Furthermore, countries compile their data in different ways which are not necessarily objective. Nevertheless, despite all these difficulties the current study compared the levels of tax complexity in countries like India, Australia, Korea, Singapore and New Zealand yielded some interesting insights.

The limitation of this study is confined to not taking the whole act of GST/VAT in to consideration and restricting the analysis to the selected chapters like Registration, Refunds, Input Tax Credit (ITC), Return Filing, Place and Value of Supply. Also, the study only considers the policy and legislative complexities and excluded the impact of taxation measured by the compliance cost measure. This can be addressed in the further research.

\section{References}

Budak, T., \& James, S. (2018). The Level of Tax Complexity: A Comparative Analysis Between the UK and Turkey Based on the OTS Index.

Evans, C., \& Tran-Nam, B. (2013). Towards the Development of a Tax System. Fiscal Studies.

Jones, G., Rice, P., Sherwood, J., \& Whiting, J. (2014). Developing a Tax Complexity Index for the UK.

UK: Office of Tax Simplification.

Katz, D. M., \& Bommarito, M. J. (2013). Measuring the Complexity of the Law: The United States Code.

Martinez, A. L., \& Silva, R. d. (2019). Tax law readability and tax complexity. SSRN.

(2013). The OTS Complexity index Version 2. UK: Office of Tax Simplification.

Waltl, B., \& Matthes, F. (n.d.). Towards Measures of Complexity:Applying Structural and Linguistic Metrics to German Laws. 153 - 162. 